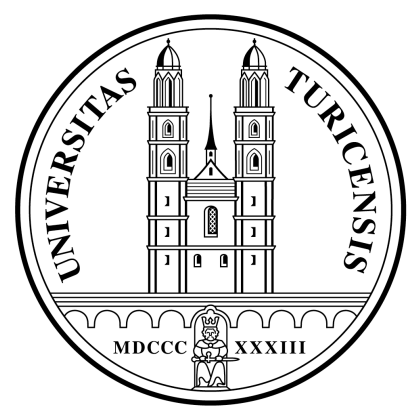

Institute for Empirical Research in Economics

University of Zurich

Working Paper Series

ISSN 1424-0459

Working Paper No. 115

Product-Market Competition in the Water Industry:

Voluntarily Nondiscriminatory Pricing

Reto Föllmi and Urs Meister

May 2002 


\title{
Product-Market Competition in the Water Industry: Voluntarily Nondiscriminatory Pricing
}

\author{
Reto Foellmi $^{*} \quad$ Urs Meister ${ }^{* *}$
}

May 17, 2002

\begin{abstract}
This paper presents an attempt to create competition in the water market by means of direct competition. We argue that the usual liberalisation device, competition for the market by franchise bidding, is problematic due to the particular features of the water industry. Our approach proposes the implementation of product market competition, i.e. competition in the market. In such a situation several water utilities using a single set of pipes compete for customers in the same area. Since the water industry is often characterised by local networks, we consider a simple model, where competition is introduced between vertically integrated, neighbouring water suppliers that connect their networks.

Even without any regulation, we show that: (i) An inefficient incumbent will give up its monopoly position and lower the access price far enough so that the low-cost competitor can enter his home market. (ii) Efficiency of production will rise due to liberalisation. (iii) In contrary to prejudicial claims, investment incentives are not destroyed by the introduction of competition. Investments of low-cost firms may even increase.
\end{abstract}

Key Words: Product-Market Competition, Water, Nondiscriminatory pricing JEL Classification: L95, L43, D21, Q25

\footnotetext{
* University of Zurich, Institute for Empirical Research in Economics, Blümlisalpstrasse 10, CH-8006 Zürich, Tel: ++41-1-634 37 26, Fax: ++41-1-634 49 07, email: rfoellmi@iew.unizh.ch.

${ }^{* *}$ Arthur Andersen, Business Consulting, Binzmühlestrasse 14, CH-8050 Zürich, Tel: ++41-1-308 19 53, Fax: ++41-1-308 18 03, email: urs.meister@.ch.andersen.com.

We thank Zava Aydemir, Stefan Buehler, and seminar participants at the IWREC Conference at Girona and the EUNIP Conference in Vienna for helpful comments.
} 


\section{Introduction}

Traditionally, network industries such as electricity, telecommunications, railways or water supply are regarded as natural monopolies. The duplication of the networks (railroad system, water pipes etc.) would not be efficient and therefore undesirable. According to this rationale, there is no reason to have several firms engaged in the market, because total output could be produced more cheaply within a single firm. For a long time the existence of natural monopolies and also other aspects such as the importance of quality issues have been a justification for the absence of direct competition. For that reason in many European countries services as telecommunications, electricity or water supply were provided by public enterprises or strongly regulated private firms.

However, in the course of privatisation and liberalisation, governments and regulators tried to expand the role of competition. Two main possibilities exist in order to implement effective rivalry into network industries: Franchise bidding, called competition for the market, and product-market competition, known as competition in the market. In the former variant, as proposed by Harold Demsetz (1968), the governmental authorities auction off the monopoly. Bidders are required to specify the tariffs they would charge for the supplied product - for a given set of performance parameters. The company promising the lowest tariffs gets the exclusive right to serve customers in the defined area. With enough bidders it is expected that a bidder reveals his minimum costs: He offers the price, which corresponds to the level of his effective average costs. In the water industry franchise bidding actually took place - for example for the Buenos Aires water and sewerage system in 1993 and also for different local systems in France. ${ }^{1}$

Theory suggests that franchise bidding is a reasonable way to implement competition in the water market. In our view, such auctions have different drawbacks, particularly in the capital-intensive water supply industry. Since parameters as technology, water quality, demand or legal aspects alter over time, the setting of prices in advance is dominated by uncertainty. Average costs are affected by modified circumstances, unwanted gains or losses in the long-term could be the consequences. To handle this problem, the governmental authorities could regulate the industry or repeat the auction frequently. However, carrying out new rounds of bidding is very costly. Furthermore Armstrong, Cowan and Vickers (1994, p. 129) indicate that a shorter holding period of the monopoly right undermine the incentives to invest into the network infrastructure. To prevent

\footnotetext{
${ }^{1}$ See Klein (1996) for further details regarding franchise bidding in Buenos Aires and France.
} 
underinvestment, the incumbent should be compensated for his effort in case of a defeat in the latest auction. If however, as Williamson (1976) argues, the regulator cannot seriously determine the actual worth of the realised investments and therefore the compensation sum, there is a serious danger of ineffective competition. ${ }^{2}$ Because of the danger of underinvestment or ineffective competition, Armstrong, Cowan and Vickers conclude that franchise bidding is unlikely to be very useful for capital-intensive elements of natural monopoly industries such as water supply networks, where capital costs are usually 70 to 90 percent of total costs.

In order to avoid these problems we suggest the implementation of product-market competition, where two or more rival companies render water services in the same area. We present a model of direct (product market) competition that takes the water sector's specific technical aspects into consideration. Our proposal is therefore based on a simple structure that allows an easy implementation of direct competition. Cowan (1997) indicates that the regulatory burden of assessing access prices for a great number of networks would be large. He follows that common carriage is not likely to be a major feature of the British water industry in the future. To avoid this regulatory problem the model assumes a baseline case, where regulation does not exist and the incumbents are fully free to set their own access fees. The model shows that even in such a worst case competition arises and significant efficiency gains can be realised.

In other network industries such as telecommunications, electricity or railways, direct competition is already implemented or at least planned. To prevent inefficient network duplication, operators are forced to give competitors access to their networks. And to secure non-discriminating access, government could either set the access prices or operate the whole network itself. The latter variant requires vertical separation of the existing companies. ${ }^{3}$ A similar liberalisation process could also be implemented in the water sector. Unfortunately, there is only a few literature about product-market competition in the water sector. Technical difficulties and the implicit assumption that water companies are natural monopolies - because the network dominates the cost structure - largely prevented such discussion. Nevertheless, the privatisation and liberalisation of the UK water industry in 1989 intended a very restricted direct competition. ${ }^{4}$

\footnotetext{
${ }^{2}$ Harstad and Crew (1999) propose a franchise-bidding-model, which addresses the mentioned valuation problem of transferred assets. However, it is necessary to assume that the entrants are informed as good as the incumbent about the value of the assets to be transferred.

${ }^{3}$ If there are significant economies of scope, however, such a separation would not be desirable. Actually, in the liberalisation process in UK, water suppliers remained vertically integrated (see section 3 below too).

${ }^{4}$ See Correia and Kraemer (1997) or Cowan (1993) and Cowan (1997) for a survey of the reform in the water industry in England and Wales.
} 
However, due to technical issues, product-market competition in the water sector differs substantially from other sectors such as telecommunications. Our model takes these aspects, which will be described in more detail in section 2, into account and explores the effects of direct competition on tariff, supply and investment behaviour. As mentioned above, we assume a baseline case where regulation - especially the regulation of access prices - does not exist. Furthermore, the incumbents stay vertically integrated, i.e. they own their (inherited) network and they sell water to final customers. Vertical integration is justified by the existence of economies of scope: Both distribution systems and water treatment facilities require sanitary know how. Although the firms remain vertically integrated and access price regulation is absent, our model shows that - under linear and non-linear access pricing - the former monopoly situation will not persist and that prices will decrease in the home market of the high-cost monopolist.

A second issue of the liberalisation debate concerns the investment behaviour of the incumbents. Due to the long-term character of investments in the water pipe network ${ }^{5}$ there is serious danger of insufficient investment expenses. According to a far-reaching prejudice incumbents neglect long-term network investments in order to improve market position and to maximise short-run profit if competition were introduced. As a result of competition, network quality would deteriorate and a considerable share of the produced drinking water would escape from the leaky water pipes. Nevertheless, despite of the absence of direct competition water today, leakage in European networks is estimated from 15 to 50 percent! European water suppliers replace on average 0,6 percent of their pipe networks yearly, while the International Water Supply Association (IWSA) recommends to replace 1,5 percent (see Skarda 1998, p. 874). This underinvestment will be one of the main future issues in the water sector and justifies the model's focus on the investment behaviour. The model does not support the prejudice mentioned above. With only weak assumptions, the model predicts increased investment incentives of the low-cost monopolist caused by the implementation of product market competition. ${ }^{6}$

The following section points out the specific structural aspects of the water sector and the corresponding implications for a competitive market. Based on these aspects we present in section 3 a realistic model of product-market competition in the water industry. The model assumes a two-stage game, where firms set investments in the first period and both output and access prices in the second period. After the determination of the cost and

\footnotetext{
${ }^{5}$ Depending on their material, water pipes have an operating life from 20 to 200 years. See Skarda (1998) p. 874.

${ }^{6}$ Remind that the regulator is not able to verify the incumbents' actual investment volume.
} 
income structure of involved water suppliers, we solve the model in section 4 by backwards-induction and analyse the incumbents' behaviour regarding output, access prices and investments. For both stages we analyse the case of linear and the case of non-linear access prices, since in practice both tariff systems are common. The conclusions in section 5 discuss the relevant policy implications.

\section{Structural Issues in the Water Sector}

In contrast to railways or telecommunications water pipe network's extension is rather local or regional than national. In most European countries communal authorities operate the water supply and the water pipe network. Since neighbouring networks are usually not connected, the utilities act as monopolists in often small local markets. In Switzerland for example there are 2'995 utilities serving 3'023 communities. More than 90 percent of the Swiss water suppliers serve an area with less than 5'000 inhabitants (see Klein and Manser 1998, p. 448). Another impressive example is Italy, where 6'600 communities are served by 13'500 utilities. However, in West Germany the number of suppliers was fallen dramatically after World War II. 1957 existed more than 15'000 utilities, 1990 less than 7'000 (see Correia and Kraemer 1997, p. 86 - 87).

The number of suppliers in an area and the network's extension is based both on the production process in the water sector and political issues. The former is mainly influenced by the quality of used raw water resources. Drinking water can be produced in three different ways: Exploiting surface waters such as lakes or rivers, pumping ground water to the surface or tapping spring water. Due to its high quality, spring water usually does not require any treatment such as screening, flocculation, clarification, filtration, the addition of chemicals or the use of ultraviolet light. Ground water usually requires a lower level of treatment than surface water, which mostly consists of poorer quality. Since treatment is a significant cost driver in water production, the use of spring water is very inexpensive while the use of surface water is most costly (see Dwr Cymru Welsh Water 1999, p. 9). Depending on the existence of such raw water resources the water suppliers' cost and tariff structures are very different. ${ }^{7}$ Water treatment causes both variable and fixed costs. Hence, economies of scale could be achieved through the centralisation of the drinking water

\footnotetext{
${ }^{7}$ In France e.g. water tariffs per cubic metre vary between 0.42 and 10.92 French Francs (see Correia and Kraemer 1997, p. 288).
} 
production, especially when the share of used surface water is extensive. On the other hand, diseconomies of scale are related to the customer's distance from storage and treatment facilities. The increasing distance indicates higher water losses and greater pumping requirements (see Zarnikau 1994, p. 190 -191). The pumping effort depends on distance and topography and causes fixed capital and variable energy costs. Another technical aspect that hinders the centralisation of drinking water production is the loss of water quality in the pipe network. The quality loss is positively correlated with transport distance: The longer water remains in the pipes, the larger gets the quality decrease. Furthermore, the capacity of several groundwater or spring water resources is very limited. The use of such relative inexpensive raw water resources indicates a decentralised water production.

Due to the existence of both economies and diseconomies of scale, different degrees of centralisation could be advantageous. In hilly or mountainous countries such as Italy or Switzerland one expects water supply to be more decentralised than in others, since farreaching networks would require a high pumping effort and the topography indicates the existence of spring water resources. ${ }^{8}$ On the other hand, the increasing use of surface water and the higher water contamination raise treatment requirements and therefore the economic need for a stronger centralisation. Such a consolidation and centralisation process was observed in countries such as Germany, Netherlands or England and Wales. In most European countries a further consolidation process is expected. Small utilities in local markets are often unable to meet growing demand or to keep raised quality standards, since the construction of new treatment facilities causes high fixed costs. ${ }^{9}$ One possibility to raise economic efficiency in water markets is to merge neighbouring utilities and to connect their networks. Utilities facing poor raw water resources could overcome capacity lacks, while other suppliers could raise their treatment facilities' rate of capacity utilisation. Hence, the merger should implement a cost efficient production structure. Cost minimum would be arrived when all involved utilities face identical marginal costs. The potential efficiency gains could be substantial, since today - as mentioned above - water suppliers' marginal costs vary significantly.

Despite such potential efficiency gains caused by the merger of neighboured utilities, it seems not to be desirable to create bigger and therefore more powerful

\footnotetext{
${ }^{8}$ In Italy the share of used spring water resources in the drinking water production amounts to 39 percent, in Switzerland 42 percent and in Germany 8 percent. The United Kingdom and the Netherlands use just ground and surface water, which require a higher level of treatment (see SVGW 1999, p. 9).

${ }^{9}$ According to Dutch studies the utility's minimal production volume should vary between 10 and 20 million cubic metre drinking water per year in order to cover the extensive share of fixed costs (see Klein and Manser 1998, p. 448). Less than one percent of Swiss utilities would meet this requirement.
} 
monopolists, which may exert political pressure e.g. to ask for exaggerated subsidies. Further, the existence of such big and powerful monopolies is often impossible due to institutional or political grounds. More importantly, the fact that there are many water networks is to be looked as an efficient answer to technological constraints, i.e. the diseconomies of scale mentioned above.

\section{Direct Competition in the Water Market: A Simple Model}

Several Swiss communities near Zurich have chosen a different way. Economically and legally independent neighbouring water suppliers connected their networks and made the commercial exchange of drinking water possible. Utilities facing poor resources purchase drinking water from nearby better suppliers in order to overcome capacity problems. ${ }^{10}$ Since the waters of the buyer and the supplier mix within the buyer's distribution system, both have the same quality obligations. But the necessity to co-ordinate the water qualities and the treatment activities considerably limits the number of involved parties and therefore the possibility to connect numerous networks - provided that all of the involved utilities produce drinking water themselves. Furthermore, diseconomies of scale caused by the above mentioned technical aspects prevent a comprehensive connection of different networks.

Our model uses an analogous approach for the implementation of product market competition. In the model, every water utility owns an inherited, exogenously given network, whose width may differ. Based on the mentioned technical issues in the water sector $^{11}$, competition between utilities takes place at a regional or local level so that only a few networks can be connected. The connection means that the - vertically integrated water utilities can compete for customers in the same area using a single set of pipes. Since favourable raw water resources such as spring and groundwater are limited and the construction of new treatment facilities causes high sunk costs, the entrance of new market participants seems to be unlikely. For this reason the model's focus on already existing

\footnotetext{
${ }^{10}$ In 1997 about 13 percent of produced drinking water in Switzerland was delivered to neighboured distribution systems (see SVGW 1999, p. 7).

${ }^{11}$ The existence of diseconomies of scale, the necessity to co-ordinate the incumbents' water qualities and treatment activities, the use of decentralised raw water resources such as spring water or groundwater and quality losses caused by the transport distance significantly restrict networks' extension and the possibility to connect different distribution systems.
} 
water suppliers, which remain vertically integrated due to economies of scope, ${ }^{12}$ seems to be realistic. In contrast to the telecommunication sector, where the former public utility owns the main share of the distribution system, the model implements a different structure where the suppliers all own a small network. To keep the analysis simple, we assume therefore that only two former monopolists (denoted by $A$ and $B$ ) connect their corresponding networks (described as 1 and 2) and enter into direct competition. ${ }^{13}$ Since drinking water mix in the connected networks, both firms supply a homogenous good. ${ }^{14}$ In the capital-intensive water industry it is natural to assume that utilities choose their quantities or capacities rather than prices (with exception of access prices). ${ }^{15}$

Using the competitor's network, each supplier is able to serve customers in the entire connected area. The corresponding grid owners charge an access fee. Incumbents could now defend their monopoly position by quoting extensive access prices. Importantly, we assume that a regulator cannot set the access price. Since the costs of using water pipe networks depend on various technical aspects (such as age or material of pipes, pumping requirements, water pressure etc.) access fees would have to be set in an individual manner. Thus, heterogeneous cost structures and asymmetric information prevent the regulator from verifying real marginal costs and therefore from assessing adequate charges.

The two firms $A$ and $B$ face heterogeneous cost functions with variable treatment costs $C_{j}(\bullet), j \in\{A, B\}$, with increasing marginal costs: $C_{A}{ }^{\prime}>0$ and $C_{A}{ }^{\prime}{ }^{\prime} \geq 0$. In addition, they face investment costs $\left(K_{j}\right)$, which do not depend on output but increase in investment. ${ }^{16}$ In order to minimise treatment costs, utilities firstly use raw water resources of high quality such as spring water. To overcome the relevant capacity constraints firms use further resources with poorer quality and therefore higher treatment requirements such as groundwater or surface water. Due to this reasoning, marginal costs of drinking water production are obviously increasing in output. Total production quantity consists of sold

\footnotetext{
${ }^{12}$ Vertical integration was also applied in the privatisation and liberalisation process of the water markets in England and Wales.

${ }_{13}$ There is a huge literature concerning network competition with "two-way interconnection" in telecommunications, e.g. Laffont et al. (1998) or Armstrong (1998). However, as Buehler (2000) notes, this literature deals mainly with the analysis of competition between symmetric firms or uses specific functional forms. Instead, our model works with general demand and cost functions and heterogeneous networks. Even more importantly, this literature has to deal with the problem that the two monopolists have to give access to each other such that consumer 1 reaches consumer 2 by telephone, this problem does not exist in the water market. Obviously, customers do not care who else is connected at the water-network.

${ }^{14}$ The model abstracts from product differentiation such as service or image.

15 The assumption of price competition with differentiated products would not change the model's results fundamentally.

${ }^{16}$ Higher investment reduces of course other fixed costs, e.g. network maintenance costs that are mainly driven by the repair work. However, the net effect of investment on output-independent cost is assumed to be positive.
} 
water and water leakage caused by leaky pipes. Water leakage $L_{i}$ in the network $i, i \in\{1$, 2 \}, decreases in network investment $I_{j}$ but does not depend on the sold quantity since water pressure has to be held constant anyway. $A$ 's relevant total cost function $T C_{A}$ reads therefore

$T C_{A}=C_{A}\left(Q_{1 A}+Q_{2 A}+L_{1}\left(I_{A}\right)\right)+K_{A}\left(I_{A}\right)$

where $Q_{1 A}$ stands for the quantity of sold water to customers in $A$ 's own network $1, Q_{2 A}$ denotes the volume of $A$ 's delivered water to customers in network 2, and $L_{1}\left(I_{A}\right)$ stands for water losses in $A$ 's own network $1 . B$ 's relevant cost function can be written simultaneously by reversing the indices.

In general, the utilities' revenues consist of three components. Firms deliver drinking water to customers connected to their own and their competitor's network, and they generate income by charging an access fee, which can consist of a variable fee $a$ and a fixed fee $F$, to their competitor. $A$ 's earnings can therefore determined as follows ( $B$ 's earnings are of course defined analogously):

$$
E_{A}=p_{1}\left(Q_{1 A}+Q_{1 B}\right) Q_{1 A}+\left[p_{2}\left(Q_{2 A}+Q_{2 B}\right)-a_{2}\right] Q_{2 A}-F_{2}+a_{1} Q_{1 B}+F_{1}
$$

where $p_{1}\left(Q_{1 A}+Q_{1 B}\right)$ denotes the inverse demand function in the market/network 1. $Q_{1 A}+$ $Q_{1 B}$ is the total quantity of sold drinking water in market $1 .{ }^{17}$ Firm $A$ 's gross revenues in the market 2 are $p_{2}\left(Q_{2 A}+Q_{2 B}\right) Q_{2 A}$. However, these revenues are reduced by the variable access price payment $a_{2} Q_{2 A}$. and the fixed access payment $F_{2}$. Finally, firm $A$ generates earnings by charging an access fee $a_{1} Q_{1 B}+F_{l}$ to its competitor $B$, which uses $A$ 's network to deliver customers in the market 1 . Putting costs and earnings together, we define firm $A$ 's profit as

$\Pi_{A}=E_{A}-T C_{A}$

Firm $A$ maximizes its profit by choosing $Q_{1 A}$ and $Q_{2 A}$, the access price $a_{1}$, which is restricted to be quantity-independent, $F_{l}$ and the investment $I_{A}$. The quality of the produced drinking water, however, is not a choice variable of the utilities. We rather assume that a

\footnotetext{
${ }^{17}$ The model abstracts from two part tariffs. Hence, water and access prices $p_{1}, p_{2}$, and $a_{2}$ are constant per unit of output. This assumption is reasonable, because variable fees actually dominate tariff structures. In Germany e.g., more than 90 percent of the water suppliers' earnings are generated by variable fees. (Correia and Kraemer 1997, p. 146).
} 
health authority sets a minimum quality standard, which can be verified by a laboratory. Profit maximizing firms will exactly meet this obligation.

The model is structured as a two-stage game. Long-term decisions are made in the first, short-term decisions in the second period. Due to the long-term character of network investments, firms set $I_{A}$ and $I_{B}$ simultaneously in the first stage. In the second period the players simultaneously set the flexible choice variables, i.e. production quantities $Q_{i j}$, access prices $a_{i}$ and $F_{i}$. Both output and access fees are assumed to be sufficient flexible and therefore set in the short-term. Firms set the quantities for both markets given the quantities chosen by the other utility. This procedure meets the traditional Cournot analysis. However, this analysis cannot be applied for the setting of access fees. The determination of access fees is a price decision. If $A$ raises access price $a_{1}, B$ reduces its engagement in the foreign market 1 , because the increased variable access price raises $B$ 's marginal costs. In order to maximize profits, $A$ must take $B$ 's behaviour into consideration. ${ }^{18}$ This suggests $Q_{1 B}$ and $Q_{2 A}$ to be a decreasing function of $a_{1}$ and $a_{2}$, respectively.

\section{Solving the Model}

\subsection{Second Stage}

\subsubsection{Linear access pricing}

We first focus the case of pure linear access pricing, where $F_{1}=F_{2}=0$. Firms simultaneously set quantities in their own and foreign market respectively network and the access prices. We assume that each competitor will supply a positive quantity in its homemarket but it may be unwilling to supply on the foreign market. The first order conditions of $A$ 's profit function (3) read therefore, where $\partial C_{A}(\cdot) / \partial Q_{1 A}=\partial C_{A}(\cdot) / \partial Q_{2 A} \equiv C_{A}{ }^{\prime}$ and $\partial p_{1}(\cdot) / \partial Q_{1 A} \equiv p_{1}{ }^{\prime}:$

$\frac{\partial \Pi_{A}}{\partial Q_{1 A}}=p_{1}^{\prime} Q_{1 A}+p_{1}-C_{A}^{\prime}=0$

\footnotetext{
18 In order to simplify the model's structure, we assume that access prices and quantities are set simultaneously in the same stage. Alternatively one could assume that at a second stage firms would set access prices and in a third stage the quantities. Such a structure would not change the model's results fundamentally.
} 


$$
\begin{aligned}
& \frac{\partial \Pi_{A}}{\partial Q_{2 A}}=p_{2}{ }^{\prime} Q_{2 A}+p_{2}-a_{2}-C_{A}{ }^{\prime} \leq 0 \text { and } Q_{2 A} \frac{\partial \Pi_{A}}{\partial Q_{2 A}}=0 \\
& \frac{\partial \Pi_{A}}{\partial a_{1}}=Q_{1 B}+\frac{d Q_{1 B}}{d a_{1}}\left(p_{1}{ }^{\prime} Q_{1 A}+a_{1}\right)+\frac{d Q_{2 B}}{d a_{1}} p_{2}{ }^{\prime} Q_{2 A}=0
\end{aligned}
$$

Due to symmetry $B$ 's first-order conditions can be written using the analogous notation

$$
\begin{aligned}
& \frac{\partial \Pi_{B}}{\partial Q_{2 B}}=p_{2}{ }^{\prime} Q_{2 B}+p_{2}-C_{B}{ }^{\prime}=0 \\
& \frac{\partial \Pi_{B}}{\partial Q_{1 B}}=p_{1}{ }^{\prime} Q_{1 B}+p_{1}-a_{1}-C_{B}{ }^{\prime} \leq 0 \text { and } Q_{1 B} \frac{\partial \Pi_{B}}{\partial Q_{1 B}}=0 \\
& \frac{\partial \Pi_{B}}{\partial a_{2}}=Q_{2 A}+\frac{d Q_{2 A}}{d a_{2}}\left(p_{2}{ }^{\prime} Q_{2 B}+a_{2}\right)+\frac{d Q_{1 A}}{d a_{2}} p_{1}{ }^{\prime} Q_{1 B}=0
\end{aligned}
$$

We want to determine how $A$ will set its access price (for $B$ the discussion would read analogously). We assume that each firm's payoff function and rationality (as reflected in the first order condition) is common knowledge. We focus on the case where $\partial \Pi_{B} / \partial Q_{1 B}=0 .{ }^{19}$ Solving equation (5') for $a_{1}$ then yields $a_{1}=p_{1}{ }^{\prime} Q_{1 B}+p_{1}-C_{B}{ }^{\prime}$. Using this expression and (4), we rewrite $A$ 's first order condition (6) regarding the access price $a_{1}$ : Total differentiation of (4') - (6') shows that $d Q_{1 B}\left(a_{1}\right) / d a_{1}<0$ and $d Q_{2 A}\left(a_{2}\right) / d a_{2}<0 .^{20}$

$$
\left.\frac{\partial \Pi_{A}}{\partial a_{1}}\right|_{\frac{\partial \Pi_{A}}{\partial Q_{1 A}}=0 ; \quad \frac{\partial \Pi_{B}}{\partial Q_{1 B}}=0}=Q_{1 B}+\frac{d Q_{1 B}}{d a_{1}}\left[p_{1}{ }^{\prime} Q_{1 B}+\left(C_{A}{ }^{\prime}-C_{B}{ }^{\prime}\right)\right]+\frac{d Q_{2 B}}{d a_{1}} p_{2}{ }^{\prime} Q_{2 A}=0
$$

Due to the non-existence of an access price regulation, each firm could easily defend its monopoly position in its origin market. If firm $A$ charged a very high access fee $a_{1}$, firm $B$

\footnotetext{
${ }^{19}$ Obviously, the case $\partial \Pi_{B} / \partial Q_{1 B}<0$ is uninteresting, since then $d Q_{1 B}\left(a_{1}\right) / d a_{1}=0$, i.e. $B$ would not react with its quantity $Q_{1 B}$ if $A$ changes its access price infinitesimally.

${ }^{20}$ Total differentiation of (4'), (5'), and (6') yields, applying Cramer's rule:$$
\frac{d Q_{1 B}}{d a_{1}}=\frac{1}{H}\left[\frac{\partial^{2} \Pi_{B}}{\partial^{2} a_{2}} \frac{\partial^{2} \Pi_{B}}{\partial^{2} Q_{2 B}}-\left(\frac{\partial^{2} \Pi_{B}}{\partial a_{2} \partial Q_{2 B}}\right)^{2}\right]<0 \text { and } \frac{d Q_{2 B}}{d a_{1}}=\frac{1}{H} C^{\prime \prime}{ }_{B} \frac{\partial^{2} \Pi_{B}}{\partial^{2} a_{2}}>0 \text {. }
$$

Note that the term in brackets has to be positive due to the $2^{\text {nd }}$ order conditions. $H$ stands for the Hessian determinant, which is negative in the optimum. Interestingly, the quantity in its "home" market $Q_{2 B}$ reacts to an access price increase of $A$ : Since $B$ reduces its engagement in market 1, marginal production costs decrease, and this leads $B$ to increase the quantity in its own network 2 .
} 
would not be interested to engage in market 1 , since its marginal costs $C^{\prime}{ }_{B}+a_{1}$ would then be too large to serve customers in network 1. For that reason $B$ would confine its engagement to the own network 2 and firm $A$ could exclusively serve customers in the market 1. If $A$ and $B$ charged each another extensive access prices, competition would not take place at all, and two independent monopolies would result, despite the connection of the networks. However, charging high access prices considerably restricts the two firms' opportunities to overcome capacity restraints or to generate additional earnings by charging access fees. Due to this trade-off, incumbents will set moderate access prices, which make interconnection and direct competition possible. To prove this statement we analyse $A$ 's behaviour regarding the setting of $a_{1}$ in an autarky case, where $Q_{1 B}=Q_{2 A}=0 .{ }^{21}$ In that case equation (7) takes the following value:

$$
\left.\frac{\partial \Pi_{A}}{\partial a_{1}}\right|_{\frac{\partial \Pi_{A}}{\partial Q_{1 A}}=0 ; \frac{\partial \Pi_{B}}{\partial Q_{1 B}}=0 \quad, Q_{1 B}=0, Q_{2 A=0}}=\frac{d Q_{1 B}}{d a_{1}}\left(C_{A}{ }^{\prime}-C_{B}{ }^{\prime}\right)
$$

Equation (8) is the central result of our model. If the left side of the equation is negative, it is profitable to reduce the access price $\mathrm{a}_{1}$ below $p_{I}-C_{B}$ ' and therefore to promote $B$ 's engagement in the market 1 . Then, to maximise its own profit, $A$ should give up its monopoly position by cutting $a_{1}$ and setting a non-discriminatory access price. Equation (8) shows that such a scenario happens, if $A$ faces higher marginal treatment costs than $B\left(C_{A}{ }^{\prime}>\right.$ $C_{B}{ }^{\prime}$ ). Relevant are the marginal costs in the status quo (autarky), where both firms operate in separated markets. Because of the problem's symmetry this statement is also valid for firm $B$. If $B$ faces higher marginal treatment costs, it opens its network to competitor $A$ by setting the access price $a_{2}$ below $p_{2}-C_{A}$, where $A$ gets profit trough market entry. We summarise this in the following proposition.

Proposition I: A vertically integrated water supplier opens its network to the competitor that produces with lower marginal costs.

\footnotetext{
${ }^{21}$ In the autarky case, the access price $a_{1}$ is so high that $B$ abandons its engagement in the market 1 . Since $a_{1}=p_{1}{ }^{\prime} Q_{1 B}+p_{1}-C_{B}{ }^{\prime}$ holds, $Q_{1 B}$ is zero when $a_{1}=p_{1}-C_{B}$ '.
} 
An analogous result could be achieved, using access price regulation by the Efficient Component Pricing Rule (ECPR). ${ }^{22}$ According to this rule market entry is only profitable for firms that are more efficient than the incumbent. As in our model, market entry only happens, if the incumbent's competitor faces lower marginal costs. However, there is no voluntary motivation to open the network, since ECPR indicates revenue neutrality for the incumbent. In this respect our model has stronger results: Incumbents facing high marginal treatment costs are able to increase profit by opening networks to more efficient competitors, since access fees are not limited by any regulator. Therefore incumbents can profit from their competitor's higher efficiency by leaving market shares to them. Decreasing sales are more than compensated by both access charges that exceed original contribution margin and reduced marginal production costs.

Different marginal treatment costs are the main condition for the existence of interconnection and therefore direct competition. In what follows we consider a situation where $A$ faces higher marginal treatment costs than $B$. Due to proposition I firm $A$ allows competitor $B$ to serve customers connected to $A$ 's distribution system. Hence, in the market 1 , a duopoly competition arises. On the other hand $A$ is not engaged in the market 2 , since $B$ has lower marginal costs. For that reason $B$ maintains its monopoly position in market 2 . Based on the additional engagement in the market 1 (denoted by $Q_{1 B}$ ), firm $B$ 's marginal costs increase (or at least do not decrease). However, the high-cost-firm $A$ reduces output $Q_{1 A}$ and therefore its marginal costs. Thus, marginal costs of both firms approach each other. In contrast to the actual situation, where utilities act de facto as monopolists in separated markets, drinking water production is now more efficient in the total of both markets. Highest efficiency would be achieved, if both firms faced identical marginal costs. However, such scenario cannot arise, since the model's equilibrium requires a difference in the firms' marginal costs. Equation (7) implies that $C_{A}$ ' must exceed $C_{B}$ ', if $Q_{1 B}>0$.

Proposition II: The introduction of competition in the water market increases efficiency of production, if utilities' marginal costs differ before liberalisation. Marginal cost differences decrease in the new equilibrium. Nevertheless, the equilibrium requires a minimal marginal cost differential. Therefore highest possible efficiency is not achieved.

\footnotetext{
${ }^{22}$ See Laffont and Tirole (1996) for a detailed survey of access price regulation and critical assessment of the ECPR rule.
} 
It is straightforward to see that the introduction of such a duopoly competition raises the volume of sold water in the competitive market 1 . Therefore, in equilibrium, price $p_{l}$ is lower as in the original monopoly situation.

Proposition III: The introduction of competition reduces retail price and raises sold water volume in the network of the high-cost incumbent.

A different effect arises in the market 2. As mentioned above, firm $B$ may face increased marginal costs due to its additional engagement in the market 1 . But higher marginal costs indicate a reduced monopoly output. Hence, retail price $p_{2}$ would rise and sold water volume $Q_{2 B}$ in the market 2 would fall. However, aggregate welfare increases with certainty due to higher efficiency of production, as stated in proposition II.

\subsubsection{Non-linear access pricing}

Again we consider the situation, where the less efficient monopolist $A$ allows competitor $B$ to serve customers connected to $A$ 's distribution system. In the above mentioned case of pure linear access pricing monopolist $A$ tends to set a positive access fee $a_{l}$ above its own marginal network costs ${ }^{23}$. For this reason utility $B$ 's relevant marginal costs, which consist of marginal treatment costs and access price $a_{l}$, are higher than total marginal production costs. Hence $B$ will limit its engagement $Q_{1 B}$ in market 1 below the socially optimal amount, which would guarantee efficiency of production. As stated in proposition II highest possible efficiency can not be achieved. However, instead of charging a pure linear access price $a_{l}$, monopolist $A$ can implement a two part access tariff by combining a fixed fee $F_{l}$ with a variable price $a_{1}$.

Reducing the variable tariff $a_{l}$ increases $B$ 's incentives to engage in market 1 , whereas monopolist $A$ decreases its own production amount $Q_{1 A}$. Since we assumed that $B$ faces lower marginal production costs than $A$, overall efficiency and therefore aggregate profit can be improved. However, according to equations (2) and (3) reducing $Q_{I A}$ and $a_{1}$ lowers $A$ 's revenues and therefore earnings. Only $B$ would profit from the above mentioned efficiency gain. By charging an additional fixed access fee $F_{l}$, monopolist $A$ can compensate such a loss. Since the fixed fee $F_{l}$ does not affect $B$ 's profit maximising

\footnotetext{
${ }^{23} \mathrm{We}$ assume marginal network costs equal to zero.
} 
behaviour at the margin ${ }^{24}, A$ can claim the entire additional aggregated profit. Charging $F_{1}$ shifts the profit, which results from the reduction of the variable fee $a_{1}$, from $B$ to $A$. Of course monopolist $A$ can not charge an infinite fee $F_{l}$, he has to meet $B$ 's participation constraint, which reads $\Pi_{B}^{\text {Autarky }}-\Pi_{B}^{\text {Access }} \geq 0$. Denoting the optimal quantities in the autarky case by $Q^{*}{ }_{2 B}$, we can write

$$
\begin{aligned}
& \Pi_{B}^{\text {Autarky }}=p_{2}\left(Q_{2 B}^{*}\right) Q_{2 B}^{*}-T C_{B}\left(Q_{2 B}^{*}\right) \quad \text { (9) and } \\
& \Pi_{B}^{\text {Access }}=p_{2}\left(Q_{2 A}+Q_{2 B}\right) Q_{2 B}+p_{1}\left(Q_{1 A}+Q_{1 B}\right) Q_{1 B}-T C_{B}\left(Q_{1 B}+Q_{2 B}\right)-F_{1}-a_{1} Q_{1 B}
\end{aligned}
$$

where equation (10) denotes gross profit minus access fees. We calculate the optimal access fees $a_{1}$ and $F_{l}$ charged by $A$. $A$ maximises its profit analogous to equation (3) by choosing the own production amount $Q_{1 A}$ and the access fee, which consists of $a_{l}$ and $F_{l}$, given the above mentioned participation constraint. We set up the relevant Lagrangian:

$$
\begin{aligned}
& L=p_{1}\left(Q_{1 A}+Q_{1 B}\right) Q_{1 A}-C_{A}\left(Q_{1 A}\right)+F_{1}+a_{1} Q_{1 B} \\
& +\lambda\left[\left(p_{2}\left(Q_{2 A}+Q_{2 B}\right) Q_{2 B}+p_{1}\left(Q_{1 A}+Q_{1 B}\right) Q_{1 B}-T C_{B}\left(Q_{1 B}+Q_{2 B}\right)-F_{1}-a_{1} Q_{1 B}\right)-\Pi_{B}^{\text {Autarky }}\right]
\end{aligned}
$$

In this case the first-order conditions for the profit maximisation problem are

$$
\begin{aligned}
& \frac{\partial L}{\partial Q_{1 A}}=p_{1}^{\prime} Q_{1 A}+p_{1}-C_{A}^{\prime}=0 \\
& \frac{\partial L}{\partial F_{1}}=1-\lambda=0 \\
& \frac{\partial L}{\partial a_{1}}=Q_{1 B}+\frac{d Q_{1 B}}{d a_{1}}\left(p_{1}^{\prime} Q_{1 A}+a_{1}\right) \\
& -\lambda\left(\left(p_{2}+p_{2}^{\prime} Q_{2 B}-C_{B}\right) \frac{d Q_{2 B}}{d a_{1}}+\left(p_{1}+p_{1}^{\prime} Q_{1 B}-C_{B}\right) \frac{d Q_{1 B}}{d a_{1}}-\left[Q_{1 B}+\frac{d Q_{1 B}}{d a_{1}}\left(p_{1}^{\prime} Q_{1 A}+a_{1}\right)\right]\right)=0
\end{aligned}
$$

Equation (13) implies that $\lambda=1$, so the last expression simplifies dramatically. We can rewrite equation (14) as follows:

\footnotetext{
${ }^{24}$ Because the fixed fee $F_{1}$ is not existent in B's first order conditions.
} 


$$
\frac{\partial L}{\partial a_{1}}=-\left(\left(p_{2}+p_{2}^{\prime} Q_{2 B}-C_{B}^{\prime}\right) \frac{d Q_{2 B}}{d a_{1}}+\left(p_{1}+p_{1}^{\prime} Q_{1 B}-C_{B}^{\prime}\right) \frac{d Q_{1 B}}{d a_{1}}\right)=0
$$

Since we know that $\frac{\partial \Pi_{B}}{\partial Q_{2 B}}=p_{2}{ }^{\prime} Q_{2 B}+p_{2}-C_{B}{ }^{\prime}=0$ we can simplify the above expression again. Inserting these two equations into equation (14') yields

$$
\frac{\partial L}{\partial a_{1}}=-a_{1} \frac{d Q_{1 B}}{d a_{1}}=0
$$

which implies that $a_{l}$ is equal to zero. The outcome is by no means surprising. We get the well known result that the variable part of a non-linear price is set equal to the marginal cost.

Since $A$ 's marginal network costs are assumed to be zero, he will reduce the variable access price $a_{l}$ to an amount which is as well equal to zero. The more efficient utility $B$ gets incentives to increase its engagement in the foreign market 1 , whereas $A$ reduces own sellings. However, monopolist $A$ maximise own profit by setting the fixed access fee $F_{l}$ in the way that the participation constraint holds with equality. Thus he extracts the full additional rent of monopolist $B$. Then the access fee $F_{l}$ is the difference between $B$ 's gross profit (before paying access fees) in case of access and $B$ 's profit in case of autarky.

Proposition IV: With a non-linear tariff monopolist A extracts the full rent of an additional efficiency gain. He will set the variable access price $a_{1}$ equal to zero and the fixed access fee $F_{1}$ such that the participation constraint of $B$ holds with equality. Therefore B increases $Q_{1 B}$ while A reduces $Q_{1 A}$ until $C_{A}$ ' is equal to $C_{B}$ '. The equalization of marginal costs guarantees highest efficiency and therefore maximum aggregated profits.

In case of charging non-linear access tariffs highest possible production efficiency will be achieved. This efficiency corresponds to the case, where only one monopolist serves both markets. Of course, this is rarely possible since there are institutional restrictions which forbid that. Big monopolies may also lead to higher x-inefficiency and to more severe informational problems of the public, which enhances, for example, rent seeking activities of the merged monopoly. 


\subsection{First Stage}

In the first period the firms take their investment decisions. The central question to answer is how the introduction of competition changes the investment incentives, in comparison to the case with two autonomous monopolists. Taking into account the optimal decisions of the second stage, we can solve the model by backward induction.

\subsubsection{Investment incentives and linear access pricing}

We firstly discuss the case of pure linear access prising. Using the Envelope theorem, the derivative of the profit function (3) with respect to investment $I_{A}$ reads

$$
\frac{d \Pi_{A}}{d I_{A}}=\underbrace{\left(p_{1}{ }^{\prime} Q_{1 A}+a_{1}\right) \frac{\partial Q_{1 B}}{\partial I_{A}}+\underbrace{\left(p_{2}{ }^{\prime} \frac{\partial Q_{2 B}}{\partial I_{A}}-\frac{\partial a_{2}}{\partial I_{A}}\right) Q_{2 A}-C_{A}{ }^{\prime} \frac{\partial L_{1}\left(I_{A}\right)}{\partial I_{A}}-\frac{\partial K_{A}\left(I_{A}\right)}{\partial I_{A}}}_{\text {2. effect }}}_{\text {1. effect }}
$$

The derivative's sign and hence the investment decision is influenced by three effects. In equilibrium, the first effect only arises within the high-cost firm whereas the second effect is only relevant in the low-cost firm. The third effect can be observed in both firms.

The first effect is negative. Higher investment decreases water losses, thus for given amounts of sold water, the marginal costs of $A$ are reduced. This induces $A$ to produce more, and this pushes $B$ out of $A$ 's market. ${ }^{25}$ On the one hand revenues of $\left(\partial Q_{1 B} / \partial I_{A}\right) a_{1}$ are lost but prices in the home market increase, which gives a gain of $\left(\partial Q_{1 B} / \partial I_{A}\right)\left(p_{1}{ }^{\prime} Q_{1 A}\right)$. Equation (6) tells us that, in equilibrium, the former effect dominates.

The second effect, which occurs only when $A$ is the low-cost firm, is ambiguous. We can identify two partial effects. By investing, firm $A$ improves its position in the foreign market and induces $B$ to reduce its quantity since marginal costs of $A$ have decreased. This argument is reflected in term $\left(p_{2}{ }^{\prime} \partial Q_{2 B} / \partial I_{A}\right) Q_{2 A}$, which is positive. The other partial effect, $\left(-\partial a_{2} / \partial I_{A}\right) Q_{2 A}$, is negative. Monopolist $B$ knows that $A$ will stay in the foreign market even with a slightly higher access charge because marginal costs of $A$ have fallen. This induces $B$ to get its part from the increased efficiency of $A$ and to increase the access price.

\footnotetext{
${ }^{25} \mathrm{We}$ assume reaction curves to be falling.
} 
Obviously, this has a negative influence on $A$ 's profits. Which partial effect dominates in total cannot be determined generally.

The third effect is the direct effect and appears in the case with separated networks too. It relates marginal cost of investment $\partial K_{A}\left(I_{A}\right) / \partial I_{A}$ to their marginal revenues, the lower cost of production $-\left(\partial L_{1}\left(I_{A}\right) / \partial I_{A}\right) C_{A}{ }^{\prime}$. Since marginal cost of production is increasing, the firm, which increases production due to liberalisation, will face higher investment incentives because with higher marginal production costs marginal revenues of investment are higher. The opposite holds for the firm that lowers production. Recall that in equilibrium, the low-cost firm will increase production whereas the output of the high-cost firm decreases. Liberalisation now decreases unambiguously their investment incentives through the first and the third effect. For the low-cost firm investment incentives increase due to the third effect, whereas the second effect is ambiguous. We conclude that the introduction of competition has an asymmetric impact on investment incentives in the sense that efficient firms want to invest even more compared to high-cost firms.

\subsubsection{Investment incentives and non-linear access pricing}

We turn now to the case of non-linear access pricing. Taking the derivatives of $A$ 's profit function ${ }^{26}$ with respect to $I_{A}$ and using again the Envelope Theorem, we get

$$
\frac{d \Pi_{A}}{d I_{A}}=\underbrace{p_{1}{ }^{\prime} Q_{1 A} \frac{\partial Q_{1 B}}{\partial I_{A}}+\frac{\partial F_{1}}{\partial I_{A}}+p_{2}{ }^{\prime} \frac{\partial Q_{2 B}}{\partial I_{A}} Q_{2 A}-\frac{\partial F_{2}}{\partial I_{A}}-C_{A}{ }^{\prime} \frac{\partial L_{1}\left(I_{A}\right)}{\partial I_{A}}-\frac{\partial K_{A}\left(I_{A}\right)}{\partial I_{A}}}_{\text {1. effect }}
$$

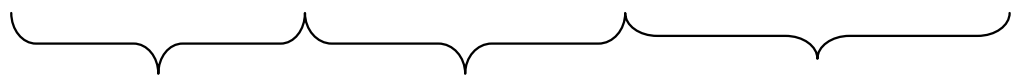

where $\frac{\partial F_{1}}{\partial I_{A}}=p_{1}^{\prime} Q_{1 B} \frac{\partial Q_{1 A}}{\partial I_{A}}$ and $\frac{\partial F_{2}}{\partial I_{A}}=p_{2}^{\prime} Q_{2 A} \frac{\partial Q_{2 B}}{\partial I_{A}}$.

Again we can distinguish three effects. The first effect captures the changes in investment incentives of the high-cost firm due to market interaction. Its sign is ambiguous. The first partial effect $\left(p_{1}{ }^{\prime} \partial Q_{1 B} / \partial I_{A}\right) Q_{1 A}$ is positive because $B$ reduces $Q_{1 B}$ when $A$ increases investment $I_{A}$ (remember that quantities are strategic substitutes in Cournot competition).

\footnotetext{
${ }^{26}$ A's profit function can be defined analogous to B's profit function, which is described in equation (10). Reversing all indices in equation (10) yields A's profit function.
} 
On the other hand the second partial effect $\partial F_{1} / \partial I_{A}$ is negative. By investing, firm $A$ reduces its marginal cost and improves its market position. This reduces $B$ 's profit. The participation constraint directly implies that $A$ must charge a lower access fee $F_{l}$.

The second effect matters only when $A$ is the low-cost firm. The effect is ambiguous as well. The reasons are exactly the same as in the first effect: On the one hand, ( $\left.p_{2}{ }^{\prime} \partial Q_{2 B} / \partial I_{A}\right) Q_{2 A}$ is positive. Due to higher investment $I_{A}, B$ reduces its quantity $Q_{2 B}$, which increases price in market 2 and $A$ 's incentives to engage in market 2. On the other hand $-\partial F_{2} / \partial I_{A}$ is negative. $B$ will increase the access fee when $A$ increases its investment. The third effect is the positive direct effect of a cost reduction. We conclude that the same effects occur in both access price schemes.

\section{Summary and Conclusions}

The non-existence of a national water grid restricts geographical extension of product market competition in the water sector to a regional or even local level. Since only few water suppliers are expected to participate in such a local competitive market, the existence of perfect competition in the market seems not to be very realistic. Nevertheless, we showed that significant efficiency and welfare gains can be achieved. The connection of neighbouring networks and the implementation of direct competition allows some suppliers to overcome their capacity constraints while others are able to raise their treatment facilities' rate of capacity utilisation. To maximise profits, utilities facing high marginal costs voluntarily open their networks to competitors and reduce own production volume, suppliers facing small marginal costs expand their production. In contrast to the former situation, where utilities act de facto as monopolists, direct competition arises and the relevant retail price in the competitive market goes down. If non-linear access tariffs are allowed, we get the even stronger result that, by introducing competition in the market, highest production efficiency is achieved.

It is important to note, that the improvement of production efficiency is achieved by the implementation of competition and not by collaboration between neighbouring utilities. The model therefore does not assume an efficient negotiation process between the market players. Competition itself leads to production efficiency in the market.

One may object that the water suppliers still have some degree of market power, despite the implementation of competition in the market. However, we show that the high 
cost firm gives up its monopoly position and prices decrease, although there is no (price) regulation. In order to address this issue further, competition in the market could be combined with additional elements of competition or with regulation - for example yardstick competition, price caps or rate of return regulation.

The model shows further that there are only weak reasons for reduced investment incentives caused by the introduction of competition. The effects are in both access pricing systems similar: on the one hand the less efficient firm reduces network investments, on the other hand the more efficient one tends to increase investments. However, it should be noted that the model assumes a worst case, where regulation does not exist at all. Both degree of competition and investment volume are expected to improve by effective regulation.

The simple structure of the model and the non-existence of any regulation suggest an easier implementation of such a direct competition than other approaches. In practice just a few structural and legal changes and of course the physical connection of neighbouring networks would be needed. Both utilities and consumers could profit from fast efficiency gains. However, today water utilities costs are dominated by fixed capital costs, above all by network investment costs. Potential efficiency gains in water treatment caused by the introduction of direct competition would be minor. But in the long-term increasing demand, capacity constraints and higher contamination of raw water resources are expected to raise treatment requirements and therefore variable costs significantly. In this sense our model helps discussing future problems in the water industry. 


\section{References}

Armstrong, Mark; Network Interconnection in Telecommunications, Economic Journal $108,1998,545-564$.

Armstrong, Mark, Simon Cowan and John Vickers; Regulatory Reform: Economic Analysis and British Experience, MIT Press, London, 1994.

Buehler, Stefan; A Further Look at Two-way Network Competition in Telecommunications. Working Paper, University of Zurich, 2000.

Correia, Francisco Nunes and Andreas Kraemer; Institutionen der Wasserwirtschaft in Europa - Länderberichte, Springer, Berlin, 1997.

Cowan, Simon; Competition in the Water Industry, Oxford Review of Economic Policy, Vol. 13, No. 1, 1997, 83 - 92.

Cowan, Simon; Regulation of Several Market Failures: The Water Industry in England and Wales, Oxford Review of Economic Policy, Vol. 9, No. 4, 1993, 14 - 23.

Demsetz, Harold; Why Regulate Utilities? Journal of Law and Economics 11, 1968, 55 65 .

Dwr Cymru Welsh Water; Water Resources and Treatment Cost Drivers, Montgomery Watson (Report), London 1999.

Harstad, Ronald and Michael Crew; Franchise Bidding Without Holdups: Utility Regulation with Efficient Pricing and Choice of Provider, Journal of Regulatory Economics 15, 1999, $141-163$.

Klein, Hans-Peter and Urs Manser; Die Struktur der Wasserversorgungen in der Schweiz, in: gwa 6/98, Zurich 1998, 447 - 451.

Klein Michael; Economic Regulation of Water Companies, The World Bank: Public Policy for the Private Sector, Washington 1996.

Laffont, Jean-Jacques, Patrick Rey and Jean Tirole; Network Competition: I. Overview and Nondiscriminatory Pricing, Rand Journal of Economics 29, 1998, 1 - 37.

Laffont, Jean-Jacques and Jean Tirole; Creating Competition Through Interconnection: Theory and Practice, Journal of Regulatory Economics 10(3), 1996, 227 - 256.

Skarda, Ctibor; Überlegungen zum Rohrnetzmanagement, in: gwa 10/98, Zurich 1998, $867-875$.

SVGW (Schweizerischer Verein des Gas- und Wasserfaches); Statistische Erhebungen der Wasserversorgungen in der Schweiz 1997, Zurich 1999. 
Williamson, Oliver E.; Franchise Bidding for Natural Monopoly - In General and With Respect to CATV, Bell Journal of Economics 7, 1976, 73 - 104.

Zarnikau, Jay; Spot Market Pricing of Water Resources and Efficient Means of Rationing Water During Scarcity, Resource and Energy Economics 16, 1994, 189 - 210. 